\title{
Investigating the fate of natural organic matter at a drinking water treatment plant in South Africa using optical spectroscopy and chemometric analysis
}

\author{
Welldone Moyo', Nhamo Chaukura', Machawe M Motsa', Titus AM Msagati', Bhekie B Mamba', Sebastiaan GJ Heijman², \\ and Thabo TI Nkambule' \\ ${ }^{1}$ Nanotechnology and Water Sustainability (NanoWS) Research Unit, University of South Africa (UNISA), Johannesburg, South Africa \\ ${ }^{2}$ Department of Civil Engineering and GeoSciences, Technical University of Delft, Delft, The Netherlands
}

\begin{abstract}
The removal dynamics of biodegradable dissolved organic carbon (BDOC) and natural organic matter (NOM) polarity fractions at a water treatment plant (WTP) in South Africa was studied using UV-Vis absorbance, fluorescence excitation-emission matrix, and two-dimensional synchronous fluorescence spectroscopy (SFS). This study gave insights into the transformation of NOM due to treatment processes. The objectives of the study were: (i) to use chemometric analysis and two-dimensional SFS correlations to investigate the evolution of NOM arising from treatment processes, and (ii) to access the chemical profile dynamics of polarity and $\mathrm{BDOC}$ fractions throughout the treatment train. The UV ${ }_{254}$ absorbance, which indicates aromaticity, reduced by $45 \%$ along the WTP. Gaussian fitting of UV-Vis data showed a decreasing trend in intensity and number of bands along the treatment process. The removal efficiency of NOM components followed the order: humiclike $(\mathrm{HL})>$ tyrosine-like $(\mathrm{TYL})>$ fulvic-like $(\mathrm{FL})>$ tryptophan-like $(\mathrm{TPL})>$ microbial-like $(\mathrm{MBL})$. At the source, the relative distribution of the hydrophobic (HPO), hydrophilic (HPI), and transphilic (TPI) fractions was $45 \%, 31 \%$, and $24 \%$, respectively. The HPI was recalcitrant to treatment, and the TYL component of the HPI fraction was conjectured to be a disinfection byproduct limiting reagent. The $\mathrm{HL}$ and FL components of the BDOC fraction were the major substrates for bacterial growth. According to two-dimensional-SFS correlation, TYL, TPL, and MBL varied concurrently across the treatment stages. Used for the first time in South Africa, the robustness of a multi-dimensional approach of optical methods coupled with chemometric tools for the assessment of the fate of NOM along the treatment processes was revealed by this study.
\end{abstract}

\section{INTRODUCTION}

The fate of natural organic matter (NOM) in drinking water treatment processes remains contentious due to the heterogeneous nature and structural complexity of NOM. Compounding this is its temporal and spatial variability, making efforts to remove it uncertain (Nkambule et al., 2012). A single set of results is therefore not enough to either project these to a new treatment system or predict future trends for an existing system. Detrimental to water treatment and distribution, $\mathrm{NOM}$ is the major contributor to the fouling of membranes and activated carbon, is a precursor to the formation of disinfection by-products (DBPs), impacts on the organoleptic properties of water, and certain fractions of NOM promote biological growth in distribution networks (Lobanga et al., 2013; Lyon et al., 2014; Hua et al., 2015; Park et al., 2016). Therefore, closely monitoring the transformation of NOM along the treatment train is essential for the management of NOM-related problems. Current research characterizes NOM with emphasis on properties such as biodegradable dissolved organic carbon (BDOC), polarity, UV absorption, fluorescence intensity, and molecular weight fractions (He et al., 2013; Chen et al., 2017; Li et al., 2017a).

Biodegradable dissolved organic carbon is the fraction of NOM that is responsible for providing heterotrophic bacteria with energy and nutrition (Li et al., 2017b). Its measurement entails quantification of the reduction of dissolved organic carbon (DOC) after a predefined timeframe, ranging from a few days to several weeks and depending on, inter alia: (i) incubation timeframe, vessel type, size, and type (batch culture, flow-through bioreactor); (ii) initial DOC concentration; (iii) supplementary nutrient additions and/or additives; (iv) type of bacterial strain, amount of inoculums, and monitored biodegradation product (change in DOC over time, evolution of carbon dioxide); and (v) temperature and frequency of measurements (Mcdowell et al., 2006; Lohwacharin et al., 2014; Marais et al., 2016; Prest et al., 2016). However, these measurement approaches are lacking in that they measure the reduction in bulk NOM over time, disregarding the fact that NOM comprises of a wide continuum of carbon (e.g fluorescent - aromatic and conjugated and nonfluorescent - aliphatic and saturated). Therefore, a measure of DOC reduction cannot adequately identify the specific DOC fraction available for mineralization by heterotrophic bacteria. Knowledge of the character of the labile fraction available for assimilation by heterotrophic bacteria is necessary for adjusting the treatment protocol to target the problematic NOM fraction and hence starve the bacteria.

Besides BDOC, the other most studied parameter of NOM is polarity. The polarity of organic matter influences its palatability by heterotrophic bacteria and is used as a measure of chemical changes caused by environmental and treatment processes (Liao et al., 2015a). Low molecular weight hydrophilic fractions of NOM are more palatable to bacteria than high molecular weight

\section{CORRESPONDENCE}

Thabo TI Nkambule

\section{EMAIL}

nkambtt@unisa.ac.za

\section{DATES}

Received: 17 January 2019

Accepted: 13 November 2019

\section{KEYWORDS}

biodegradable dissolved organic carbon natural organic matter optical spectroscopy two-dimensional correlations water treatment

\section{COPYRIGHT}

(c) The Author(s) Published under a Creative Commons Attribution 4.0 International Licence (CC BY 4.0) 
hydrophobic fractions (Chen et al., 2014). However, the available analytical techniques are not capable of concurrently characterizing NOM polarity fractions under prevailing environmental settings.

The polarity rapid assessment method (PRAM) partitions NOM based on adsorption preference onto solid-phase extraction (SPE) sorbents (Rosario-Ortiz et al., 2004a). Studies on PRAM characterization applied to precursors of nitrogenous DBPs reported higher selectivity than the conventional XAD resin approach (Chen et al., 2016). Another study modified the PRAM method by eluting the fractions sequentially instead of the parallel elutions of fractions producing three fractions, namely, the hydrophobic, hydrophilic and transphilic fractions (Nkambule., 2012a). PRAM fractionation has been widely applied to the bulk NOM without further analysis of the produced fractions (Rosario-Ortiz et al., 2007b; Nkambule., 2012a; Chen et al., 2014; Liao et al., 2015b). Therefore, additional analysis of the fractions can be performed to reveal more information on the characteristics of the fraction. To this end, this study used fluorescence excitation-emission matrix (FEEM) spectroscopy for an in-depth investigation of the polarity and BDOC fractions character.

Fluorescence spectroscopy is a robust tool for characterizing fluorescent dissolved organic matter (FDOM) in various natural and engineered aquatic systems (Baghoth et al., 2010; Sanchez et al., 2013; Tijani et al., 2014; Zhang et al., 2015). Owing to simplicity in application, FEEM spectroscopy has promise in predicting the removal of NOM during both conventional and advanced drinking water treatment processes (Kastl et al., 2016; Wang and Benjamin, 2016; Li and Hur, 2017). Coupled with multivariate statistical methods such as parallel factor analysis (PARAFAC), self-organizing maps (SOM), principal filter analysis (PFA), and fluorescence regional integration (FRI), EEMs have been used to identify NOM components and provide further insight into the environmental dynamics of NOM in diverse aquatic ecosystems (Henderson et al., 2009; Bieroza et al., 2011; Korak et al., 2013; Sanchez et al., 2013).

Complementary to the FEEM spectra, synchronous fluorescence spectroscopy (SFS) shows advantages of better spectral deconvolution, light dispersion reduction, and well-resolved peaks and shoulders (Guo et al., 2013; Costa et al., 2016). Coupling two-dimensional correlations to SFS (2D-SFS) produces a powerful chemometric tool that can resolve superimposed peaks by extrapolating them to the second dimension. This can also be used to determine the order of spectral changes in response to external perturbations (Chen et al., 2017). The combination of these techniques in the assessment of NOM fractions provides data on the character of NOM at each treatment stage.

Herein, we propose the assessment of NOM and its BDOC and polarity fraction dynamics with insights from UV-Vis absorbance with Gaussian fitting, FEEM, and 2D-SFS for tracking NOM transformation throughout the treatment train. The majority of treatment plants in South Africa follow the conventional treatment processes, with flocculation-coagulation as the major organics removal stage, and chlorination at the disinfection stage (Nkambule et al., 2012; Marais et al., 2016; Chaukura et al., 2018). To the best of our knowledge, this is the first study conducted in South Africa to investigate the occurrence, fate, and removal efficiencies of specific NOM fractions including in-depth transformations of BDOC and polarity fractions brought about by the treatment processes. The objectives of the study were to: (i) investigate the fate of NOM and subsequent transformations brought about by treatment processes; (ii) evaluate the chemical profile dynamics of polarity and BDOC fractions throughout the treatment train; and (iii) apply 2D-SFS correlation for the assessment of dynamic spectral properties of NOM due to water treatment processes.

\section{MATERIALS AND METHODS}

\section{Bulk sample analysis}

\section{Sampling}

Sampling was conducted at a water treatment plant in the Gauteng Province of South Africa. The plant has a maximum treatment output of $42 \mathrm{ML} \cdot \mathrm{day}^{-1}$. Triplicate samples were collected after each treatment stage. The treatment processes involve coagulation/flocculation using a combination of ferric sulphate and a commercial organic flocculant with $\mathrm{pH}$ correction using lime, followed by dissolved air floatation filtration (DAFF) through sand beds, and finally chlorination. Portable multimeters were used to measure turbidity, $\mathrm{pH}$, temperature, and conductivity on site. Samples were transported to the laboratory in ice boxes and then filtered using a $0.45 \mu \mathrm{m}$ $\mathrm{GF} / \mathrm{F}$ filters (Sigma Aldrich, Germany) prior to storage at $4^{\circ} \mathrm{C}$ and analysed within $48 \mathrm{~h}$.

\section{Dissolved organic carbon, fluorescence and UV absorbance analysis}

The filtered samples were analysed for DOC using a total organic carbon analyser (Teledyne Tekmar, TOC fusion). Fluorescence EEMs and absorbance spectra were measured in the wavelength range $200-800 \mathrm{~nm}$ at $\Delta \lambda=2 \mathrm{~nm}$ excitation intervals, and 248.58-830.59 $\mathrm{nm}$ at $\Delta \lambda=3.28 \mathrm{~nm}$ emission intervals using a fluorescence spectrometer (Aqualog, HORIBA, Jobin Yvon). To determine the overall removal of NOM and efficiency of the treatment steps, the UV absorbances of water samples were measured at a wavelength, $\lambda=254 \mathrm{~nm}\left(\mathrm{UV}_{254}\right)$. The character of the three fractions (hydrophobic, hydrophilic, transphilic) obtained through the polarity rapid assessment method (PRAM) was also analysed using $\mathrm{UV}_{254}$ measurement. Further, simulated synchronous fluorescence spectroscopy at a wavelength offset of $\Delta \lambda=18 \mathrm{~nm}$ was used to study the fluorescence characteristics of water samples collected after each treatment stage at the same wavelength range as the EEMs (Guo et al., 2013).

\section{In-depth NOM fraction analysis}

\section{Polarity rapid assessment method}

The modified-polarity rapid assessment method (m-PRAM) was used to partition NOM into three fractions, namely: the hydrophobic (HPI), hydrophilic (HPO) and transphilic (TPI) fractions (Nkambule et al., 2012). In this method, a 24-position vacuum manifold (Sigma Aldrich, Germany) was connected to a vacuum pump operated at 5 inches $\mathrm{Hg}, 10 \mathrm{kPa}$, and $20 \mathrm{~mL}$ glass test tubes were used for collecting the SPE filtrate. The C18 (nonpolar), $\mathrm{CN}$ (polar) and $\mathrm{NH}_{2}$ (weak anionic) cartridges, each of size $500 \mathrm{mg}$, and volume $6 \mathrm{~mL}$ were operated in series to retain HPO, HPI, and TPI, respectively. Sufficient clean-up of the cartridges was used to curb carbon leaching and obtain reproducible results. Methanol $(15 \mathrm{~mL})$ was filtered at a rate of one drop per second until 1-2 $\mathrm{mm}$ of the methanol layer was left above the media; thereafter $500 \mathrm{~mL}$ deionised water in $100 \mathrm{~mL}$ aliquots was added to each cartridge to wash off the residual methanol and loose organic matter until a steady-state $\mathrm{UV}_{254}$ was obtained. Thereafter, $20 \mathrm{~mL}$ of sample was introduced into the cartridges sequentially starting with $\mathrm{C} 18$ cartridge; the permeate thereof was introduced into the $\mathrm{CN}$ cartridge, then ultimately to the $\mathrm{NH}_{2}$ cartridge. About $10 \mathrm{~mL}$ $0.1 \mathrm{M} \mathrm{NaOH}$ was passed through the $\mathrm{C} 18$ and $\mathrm{CN}$ cartridges to elute the HPO and HPI fractions, respectively. The TPI was the fraction which was not retained by the $\mathrm{NH}_{2}$ cartridge. 


\section{Biodegradable dissolved organic matter}

An inoculum of biologically active sand (BAS) was collected from the DAFF beds at the WTP. Excess carbon in the sand was removed by washing with $0.1 \mathrm{M}$ sodium thiosulphate solution until a steady $\mathrm{UV}_{254}$ absorbance close to zero was obtained. Thereafter, the sand was rinsed in deionized water and the supernatant analysed for DOC, $\mathrm{UV}_{254}$, and fluorescence, and used as the baseline. The washed sand (100 g) was placed in 500-mL Erlenmeyer flasks covered with aluminum foil, and the water sample $(300 \mathrm{~mL})$ was added. Three solution concentrations of glucose $\left(5,8\right.$ and $\left.10 \mathrm{mg} \cdot \mathrm{L}^{-1}\right)$ were used as control. The flasks were incubated at $22^{\circ} \mathrm{C}$ in a water bath for 5 days, and daily measurements of DOC, $\mathrm{UV}_{254}$, and fluorescence were carried out.

\section{Chemometric analysis}

\section{Fluorescence regional integration of removed fractions}

The EEM spectra were divided into 5 wavelength-dependent regions representative of specific components of NOM (TYL, TPL, FL, MBL, and HL) (Ejarque et al., 2017). The equations for the calculations of the quantity of respective components under the EEM curve is shown in Box 1 (He et al., 2013).

Box 1. Equations used to determine the quantitative contribution of each region

$$
\begin{aligned}
& \theta_{i}=\sum_{e x} \sum_{e m} I\left(\lambda_{e x} \lambda_{e x}\right) \Delta d \lambda_{e x} \Delta d \lambda_{e m} \partial \\
& \theta_{T o t, 5}=\theta_{\text {Tot }, 5}=\sum_{i=1}^{5} \theta_{i_{i, 5}} \\
& P_{i, n}=\frac{\theta_{i, 5}}{\theta_{\text {Tot }, 5}} \times 100 \%
\end{aligned}
$$

where $\theta_{i}$ is the volume bound by region $i$ and $\theta_{\text {Tot, } 5}$ is the total volume of all five regions; the specific region is denoted by number $n$; and $P_{i, n}$ is the percentage volume of specific region $i$.

FRI was applied in the quantification of fractions making up the BDOC fraction:

$$
\mathrm{BDOC}_{\mathrm{EEM}}=\mathrm{EEM}_{\text {dayl }}-\mathrm{EEM}_{\text {day5 }}
$$

\section{Parallel factor analysis}

PARAFAC model was generated using the SOLO software (Eigenvector Inc, USA) which is inbuilt in the fluorescence spectrometer (Aqualog, HORIBA, Jobin Yvon). Disproportionate leverage that affects the validation of the model was corrected by disregarding fluorescence intensity below $240 \mathrm{~nm}$. Nonnegativity constraints were applied for all models, and outlier tests and leverage plots were used to exclude outlier samples from the dataset. The PARAFAC modeling was validated using a series of predetermined criteria according to Murphy et al. (2013): (i) core consistency examination, (ii) spectral loading shape evaluation, (iii) contribution of the influence of specific sample or wavelengths on the leverage, (iv) analysis of the residual, and (v) the split half criterion. Following validation, the quantitative distribution of the components after each treatment stage was quantified using their maximum fluorescence intensities $\left(F_{\max }\right)$, In-depth information on the PARAFAC model can be accessed in Murphy and Stedmon (2017).

\section{Gaussian fitting}

The PeakFit v4.12 curve-fitting software was employed to deconvolute the UV-Vis spectrum and fit the Gaussian peaks.
The location of the maxima, intensity, and energy of each Gaussian peak characterized the extent and efficiency of each treatment process. Prior research (e.g., Dryer et al., 2008a; Dryer et al., 2008b) revealed that these bands have a Gaussian nature when expressed in photon energy (Eq. 2):

$$
E(\mathrm{eV})=\frac{1240}{\lambda(\mathrm{nm})}(\mathrm{nm})
$$

\section{Two-dimensional correlation spectroscopy}

Two-dimensional correlation synchronous fluorescence spectroscopy was conducted to determine the rate of compositional variation of NOM due to the impact of treatment using the '2Dshige software' (Kwansei-Gakuin University, Japan). The order of treatment was the external perturbation. Noda and Ozaki provide a detailed description of the algorithms used in the 2Dshige software (Chen et al., 2017). In brief, 2D-SFS produces a synchronous and asynchronous map, auto-peaks and cross-peaks characterize a synchronous map and the peaks are located along the 1:1 slope line and off the diagonal line, respectively, while cross peaks characterize asynchronous map. These peaks are either positive or negative to show the sequential order of dynamic spectral variations.

\section{RESULTS AND DISCUSSION}

\section{Removal of bulk parameters}

There was a $45 \%$ reduction in $\mathrm{UV}_{254}$ absorbance along the WTP (Fig. 1). This indicates the WTP has the capacity to significantly reduce the aromatic content of NOM throughout the treatment stages. Disinfection was the major contributor to $U_{254}$ reduction (27\%). This is attributed to the reduction of activated aromatic rings, conjugated double bonds, and long aliphatic chains of NOM to smaller and hydrophilic organic fractions by chlorine (Hur et al., 2014; Golea et al., 2017). Coagulation/flocculation and DAFF contributed $12.9 \%$ and $12.7 \%$, respectively, to the elimination of $\mathrm{UV}_{254}$ absorbance. Although coagulation is usually the major NOM removal process, research has shown that SUVA $<2 \mathrm{~L} \cdot \mathrm{mg}^{-1} \cdot \mathrm{m}^{-1}$ implies that the major portion of NOM in the water is of non-humic substances and that less than $25 \%$ should be removed when SUVA $<2$ (Lavonen, 2015). $\mathrm{UV}_{254}$ is used in the water treatment industry to indicate organic matter containing conjugated functional groups with high aromatic rings and with characteristic $\pi-\pi^{*}$ electron transitions, typical for groups containing alkenes and carbonyl bonds, an attribute of humic substances (Matilainen et al., 2002; Li and Hur, 2017). Therefore, $\mathrm{UV}_{254}$ can be used as a semi-quantitative indicator of the concentration of NOM in natural waters. The results indicate that the water is mainly non-humic with poor removal by coagulation. Additional to $\mathrm{UV}_{254}$, several absorbance-related ratios have been proposed as tools for characterizing NOM ( $\mathrm{Li}$ and Hur, 2017). For instance, the ratio $\mathrm{UV}_{253} / \mathrm{UV}_{203}$ has been used as an indicator for the propensity to form DBPs during water treatment. Aromatic rings rich in $-\mathrm{OH},-\mathrm{COOH}$, $\mathrm{RCOR}$, and -COOR groups give a high quotient, whereas a low quotient is expected from unsubstituted aromatic rings (Li et al., 2017a). The average of the $\mathrm{UV}_{253} / \mathrm{UV}_{203}$ ratio decreased along the WTP from 0.129 raw to 0.080 final water, indicating the treatment regime progressively destabilized the aromatic structures, consequently lowering the potential to form hazardous DBPs.

Specific UV absorbance values reduced along the WTP from $1.456 \pm 0.025 \mathrm{~L} \cdot \mathrm{mg}^{-1} \cdot \mathrm{m}^{-1}$ to $1.204 \pm 0.020 \mathrm{~L} \cdot \mathrm{mg}^{-1} \cdot \mathrm{m}^{-1}$ at final water (Fig. 1). The hydrophobic character as measured by SUVA decreased down the treatment train, with a significant reduction $(p<0.05)$ observed during the disinfection (18\%) treatment 
step. SUVA $<2 \mathrm{~L} \cdot \mathrm{mg}^{-1} \cdot \mathrm{m}^{-1}$ indicates a hydrophilic character of NOM; this fraction is often recalcitrant to treatment (Marais et al., 2017). Because of this, it was expected that coagulation should not cause a substantial reduction in NOM (11.6\%). Another probable contributing factor to the low NOM removal at this stage could be due to the high $\mathrm{pH}$ value (7.29), which offsets the optimal function of coagulants such as ferric salts, whose optimum pH range is 4-6 (Swartz et al., 2004). Research has shown that SUVA gives an indication of the composition of NOM so that treatment processes can be tailored for its removal (Roccaro et al., 2015). SUVA is a semi-quantitative measure of the aromatic and hydrophobic character of the organic matter (Aschermann et al., 2016).

\section{Perturbations of latent features of the UV-Vis absorbance spectra throughout the treatment stages}

Gaussian fitting on DOC-normalized spectra was processed to identify the bands making up the spectra (Fig. 2). A very close fit of the experimental data and the Gaussian distribution bands was observed $\left(R^{2}>0.995\right)$. The contributing bands were operationally named: A01 (<240 nm), A02 (4.66 eV or $266 \mathrm{~nm})$, A03 (4.16 eV or $298 \mathrm{~nm}), \mathrm{A} 04(3.84 \mathrm{eV}$ or $323 \mathrm{~nm}), \mathrm{A} 05(3.49$ $\mathrm{eV}$ or $355 \mathrm{~nm}), \mathrm{A} 06(3.25 \mathrm{eV}$ or $381 \mathrm{~nm})$ and $\mathrm{A} 07(3.02 \mathrm{eV}$ or $411 \mathrm{~nm}$ ). Literature reported similarly positioned Gaussian bands obtained after deconvolution of UV-Vis spectra (Dryer et al ., 2008; He et al., 2015). Band A01 peaks at wavelength $(\lambda)$ less than $240 \mathrm{~nm}$; consequently it could not be effectively resolved by the deconvolution. Additionally, at $\lambda<240 \mathrm{~nm}$ there are spectral interferences from nitrates, nitrites, and inorganic ions (Roccaro., 2015). Thus, spectra at wavelengths less than $240 \mathrm{~nm}$ are not discussed further in this study.

The electron transfer band of benzene at approx. $253 \mathrm{~nm}$ is related to band position A2 (254-260 nm) (Korshin et al., 2017). Band A3 (270-280 nm) was ascribed to $\pi \rightarrow \pi^{*}$ electron transitions

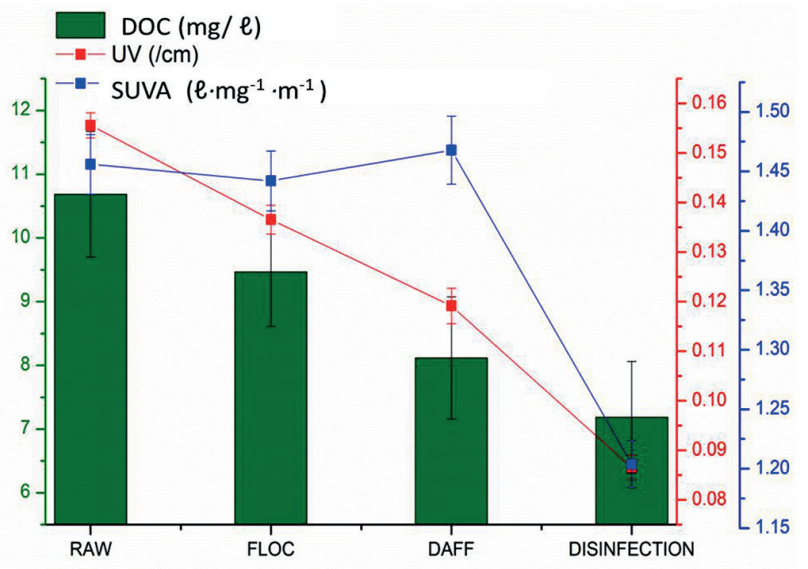

Figure 1. Bulk NOM removal parameters

of phenolic arenes and aniline derivatives substituted by at least two rings (Sharpless and Blough, 2014). At present, there is not enough evidence to state with certainty that the band A03 can be assigned to specific DBPs' formation. More research exploring changes in the intensity, position, and shape of this band characteristics is required. However, it is established that connections exist between the intensity of the differential absorbance at $272 \mathrm{~nm}$ and individual DBPs (Korshin et al., 2007; Lavonen, 2015). The intensities of all bands decreased at the disinfection stage and, interestingly, bands in the longer wavelength (i.e. A05, A06, and A07) disappeared at this stage. Absorption at long wavelengths is usually due to intramolecular charge transfer brought about by electron donor/acceptor interactions (Sharpless and Blough, 2014). Such interactions are low energy transitions prone to chemical and biological reactions, and are hence sensitive to treatment processes and can thus be easily removed.
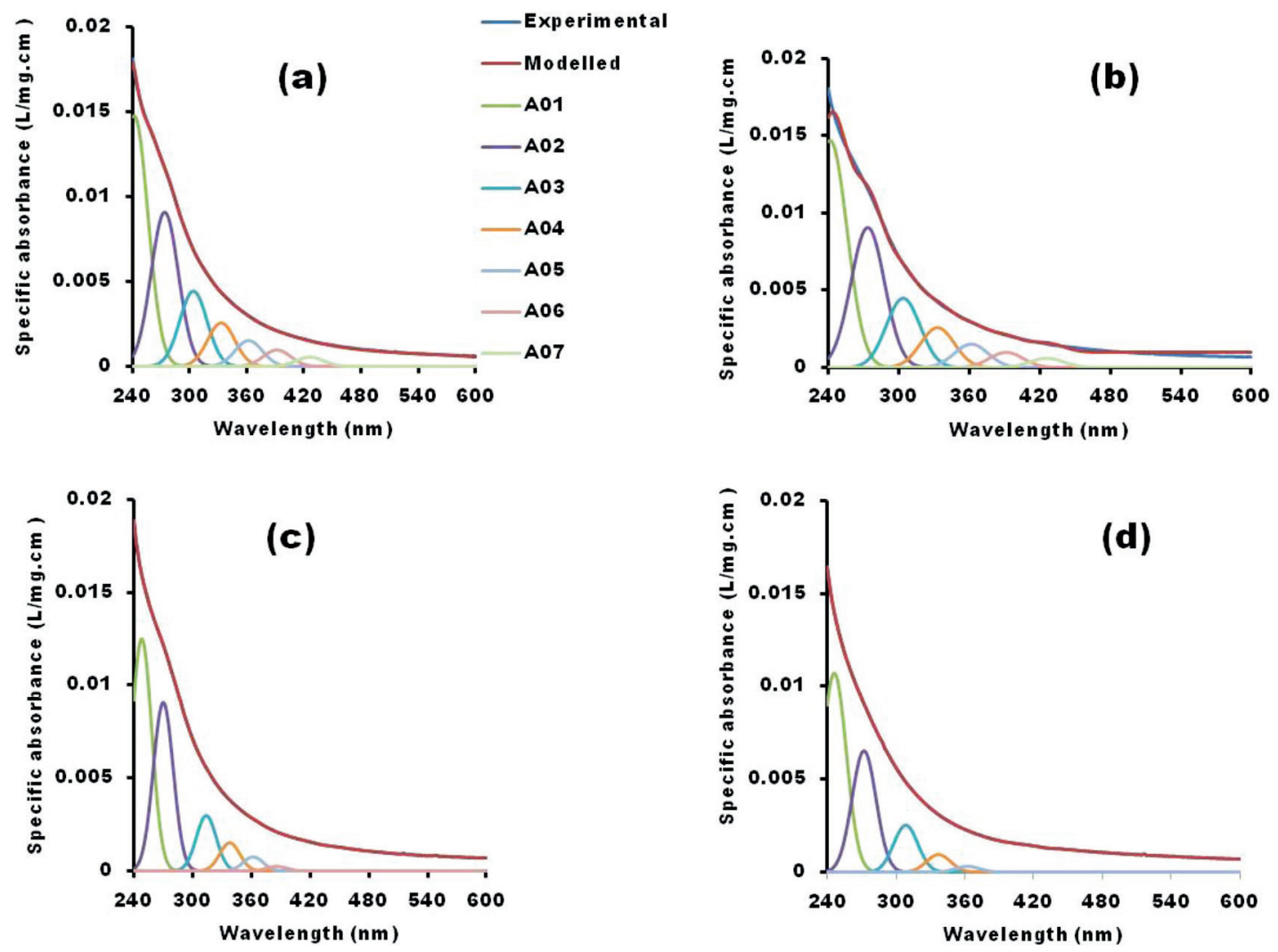

Figure 2. Gaussian band fitting of UV-Vis absorbance spectra of (a) raw; (b) flocculation; (c) DAFF and (d) disinfection samples 
It is noteworthy that the intensities of the bands reduced at specific treatment stages. However, the positions of the maxima of the Gaussian bands did not change considerably at specific treatment stages. The reduction of intensity of these bands is a measure of the efficiency of the WTP in removing chromophoric moieties. In previous studies, Gaussian decomposition of absorbance spectra has proved to be a useful tool in probing the changes in the molecular structures of NOM (Yang et al., 2017).

\section{In-depth NOM fraction analysis at each treatment stage}

\section{Polarity fractionation dynamics along the treatment train}

At the source, the relative distribution of the HPO, HPI, and TPI was $45 \%, 31 \%$, and $24 \%$, respectively (Fig. 3a). These results are in agreement with previous reports that surface water NOM consists of about $50 \%$ of HPO while the hydrophilic fraction contribution ranges from $25-40 \%$, and the transphilic fraction occupies the remainder (Universiti et al., 2016). The WTP reduced the hydrophobic fraction from $45 \%$ content in raw water to $36 \%$ in final water. Previous studies have indicated that the HPO fraction is most amenable to removal in conventional treatment processes compared to other fractions (Kim and Yu, 2005; Knowles, 2011; Baghoth, 2012; Hesham et al., 2013). However, this was not the case in this study because the water had low SUVA values, and for SUVA $<2 \mathrm{~L} \cdot \mathrm{mg}^{-1} \cdot \mathrm{m}^{-1}$ it is expected that less than $25 \%$ of HPO fraction should be removed (Lavonen, 2015).

There was no significant difference between the quantity of the HPI fraction in the raw and final water $(p<0.01)$. However, there was a significant drop in the hydrophilic fraction at the disinfection stage from $41 \%$ to $33 \%$. The HPI has high THM and HAA formation potential for waters with low humic content characterized by low SUVA compared to the HPO fraction (Karapinar et al., 2014). Additionally, the HPI fraction is characterized by a low $\mathrm{C} / \mathrm{O}$ ratio and SUVA $<2$ is indicative of less aromatic carbon content (Marais et al., 2017). Therefore, it can be conjectured that the drop in the HPI fraction was due to the formation of DBPs. Treatment options such as coagulation are not effective for removing this type of fraction (Bond et al., 2010; Matilainen et al., 2010; Sarathy et al., 2011). There was a $6 \%$ drop in quantity of HPO and a $6 \%$ increase in quantity of HPI accompanied by a $12.7 \%$ decrease of UV-Vis absorbance at the DAFF stage. The drop in the HPO fraction at this stage is attributable to microbial degradation of high molecular conjugated aromatic structures to simpler aliphatic compounds in the sand filter beds. Heterotrophic bacteria transform NOM by degrading organic matter rich in carbonyl and hydroxyl groups, which elevates the HPI content at the expense of HPO concentrations (Universiti et al., 2016). There was no significant reduction $(p<0.01)$ in the transphilic fraction throughout the treatment stages.

The impact of the treatment stages on the EEM spectra of the PRAM fractions was quantitatively analysed using the FRI technique (Fig. 3b). At all treatment stages, the intensity of HPO in Region $\mathrm{V}$ was higher than in other regions. This was expected because this is the fingerprint region for the HPO fraction. Region V is due to the HL fluorescence, while Region IV describes the microbial by-products' fluorescence, and Region III is for FL material. Regions I and II are due to protein-like fluorescence (TYL and TPL, respectively) (Chen et al., 2003). It was of interest to carry out an in-depth study of the compositional variation of HPI because it is the main predecessor to THM and HAA formation in low-humic water such as in this case (Universiti et al., 2016).
The evolution of the HPI component throughout the treatment train showed the TYL component had an upward trend (20-50\%) while the HL component declined (51-18\%) from raw to DAFF. This suggests the treatment processes were able to break down the humic fraction into simpler fractions which mimicked a proteinaceous-like spectral signature. Notably, there was a $14 \%$ decline in the TYL component and an $11 \%$ increase of the HL component at the disinfection stage. The reason could be the formation of DBPs whose spectral signature was similar to the HL component. These findings suggest the TYL component of the HPI fraction is the DBP-limiting reagent. Therefore, sequestrating proteinaceous material before the disinfection stage should subsequently reduce DBP quantity.

\section{The dynamics of biodegradable dissolved organic carbon along the treatment train}

The BDOC for raw water was $5.07 \pm 0.99 \mathrm{mgC} \cdot \mathrm{L}^{-1}$ measured as DOC (Fig. 4a), which was higher than reported values for surface waters (Charnock and Kjonno. 2000, 0.21-2.79 mgC. $\mathrm{L}^{-1}$; Najm et al., 2000, 0.05-0.85 $\mathrm{mgC} \cdot \mathrm{L}^{-1}$; Volk and LeChevallier., 2002, 0.03-1.03 $\left.\mathrm{mgC} \cdot \mathrm{L}^{-1}\right)$. This is probably because the DOC of this study area was more amenable to bacterial attack than that reported in literature. BDOC is traditionally measured as a change in DOC over a timeframe with no further regard given to DOC composition (Nkambule et al., 2012a). The BDOC fraction progressively decreased from raw, flocculation, DAFF, and disinfection $(47 \%, 39 \%, 38 \%$ and $11 \%$, respectively), as the water was losing its hydrophobic character $\left(R^{2}=0.87\right)$. It

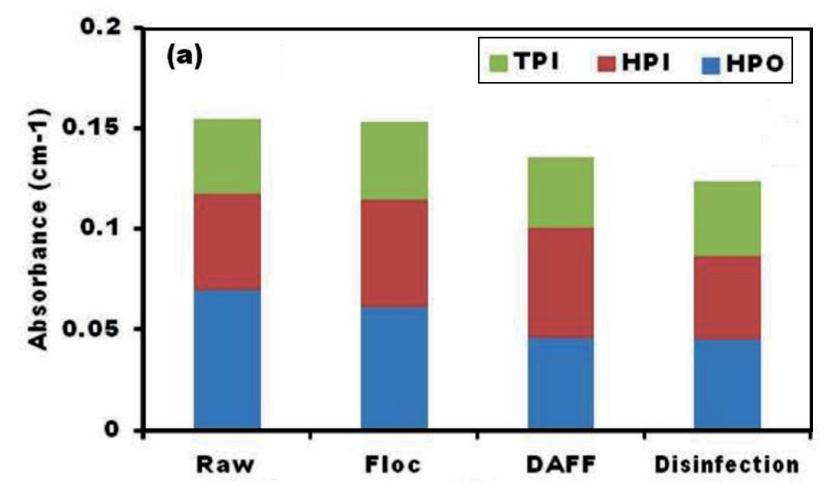

(b)

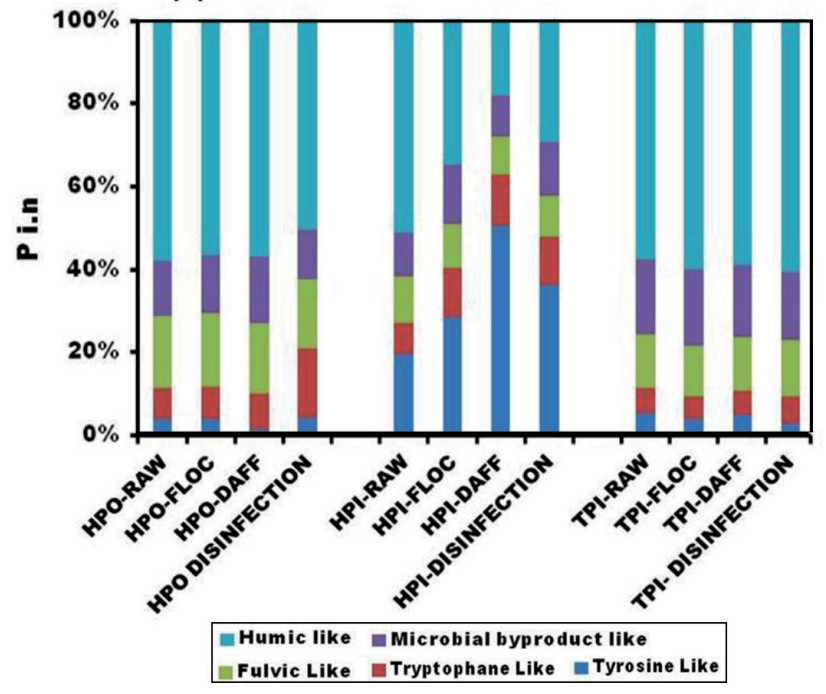

Figure 3. (a) Polarity fraction dynamics throughout the treatment stages; (b) compositional changes of polarity fractions in response to the treatment protocol 
has been reported that water with high humic content is more susceptible to biodegradation than low humic waters (Volk et al., 2000). Samples at disinfection showed the lowest BDOC fraction value because it had the lowest DOC content; therefore the change in DOC was minimal compared to other treatment stages. This result is contrary to previous studies which reported an increase in the BDOC fraction at the disinfection stage (Terry and Summers, 2018). Overall, the quantity of the BDOC fraction upon disinfection depends on the quantity and quality of NOM, chlorine dosage, and contact time (Dong et al., 2014).

By definition, BDOC is the fraction of DOC taken up and mineralized by heterotrophic microorganisms within a predefined timeframe (Terry and Summers, 2018). It was of interest to follow BDOC dynamics throughout the creation stages conceptually depicted here by the raw water sample so that the specific components making up the BDOC fraction can be tracked for the purposes of identifying the most amenable component for uptake by heterotrophic bacteria (Fig. $4 \mathrm{~b}$ ). It was observed that the FL fraction increased (19\%) while the proteinaceous fractions increase was $5 \%$ and $23 \%$ for TPL and TYL, respectively, and the HL fraction declined (4\%) from Day 1 to Day 2, corresponding to a $44 \%$ decline in DOC in the same period (Fig. $4 \mathrm{~b}$ insert). The increase in proteinaceous material was perhaps due to some species of heterotrophic bacteria secreting extracellular polymeric enzymes to break down the substrate for ease of assimilation whilst in the process consuming HL material (Universiti et al., 2016). The disproportionate decrease in DOC was probably due to other non-fluorescent sources of carbon contained in the DOC available for uptake by the heterotrophic bacteria. From Day 2 to Day 3 all fractions showed a decreasing trend, with FL and HL having the greatest decline (28 and $17 \%$, respectively), while proteinaceous matter showed the least decrease (each less than $8 \%$ ). At this stage, the implications are that the heterotrophic bacteria have acclimatized to the available substrate (mainly FL and HL) (Filip et al., 2000). The downward trend of FL and HL persisted throughout the study period. Previous reports indicate that humic matter is the preferred material for uptake by heterotrophic bacteria (Prest et al., 2016). From Day 3 to Day 4 there was a spike in TPL (26\%) and TYL (20\%) with a corresponding $40 \%$ rise in DOC. This is the point of cell death where the bacteria had outgrown the available nutrients (Terry and Summers, 2018). The rise in DOC was thus attributed to dead bacteria plus the non-fluorescent and/or nonbiodegradable organic matter (Terry and Summers, 2018). Day 4 to Day 5 saw a decline in all fractions with TPL and TYL, giving a $25 \%$ reduction each with a corresponding $27 \%$ decline in DOC. At this point, the dead bacteria served as substrates for higher bacteria or other organisms in the food chain. According to the FRI results, the contributions of HL, FL, MBL, TYL and TPL were $27 \%, 19 \%, 5 \%, 6 \%$ and $5 \%$, respectively, to the total BDOC fraction (Fig. 4c). These results suggest HL and FL are the major substrates for bacterial assimilation. Control and monitoring of these fractions is thus necessary to curb the concentrations of BDOC.

The management of the BDOC fraction is crucial because, if left unchecked, it is this fraction of DOC that is responsible for bacterial regrowth in the water distribution system. The $\mathrm{BDOC}$ fraction is also responsible for the alteration of the physicochemical properties of the treated water, impacting on taste and odour, elevation of turbidity, and loss of residual chlorine, subsequently increasing the formation potential of DBPs (Vital et al., 2010; Li et al., 2017b).

\section{Fluorescent NOM fraction dynamics at each treatment stage}

\section{NOM characterization using synchronous fluorescence spectra}

Representative synchronous fluorescence spectra of the raw water and after various treatment stages at an interval of $\Delta \lambda=18 \mathrm{~nm}$ are illustrated in Fig. 5a and quantitative distributions of fluorescent fractions are shown in Fig. 5b. PARAFAC analysis was carried out

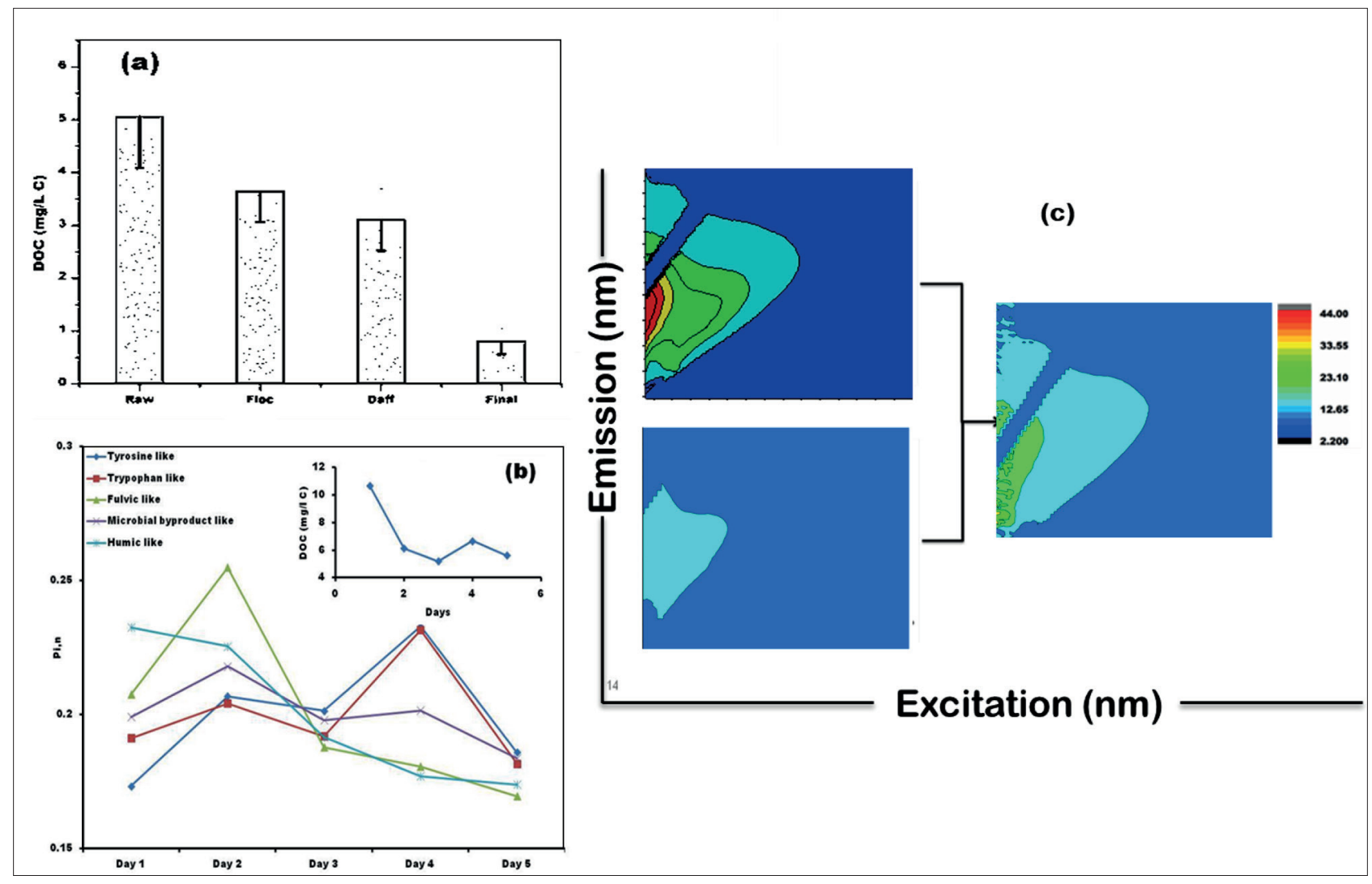

Figure 4. (a) BDOC fraction dynamics throughout the treatment train; (b) BDOC compositional dynamics throughout the formation stages and (c) BDOC fraction EEM spectra 
to complement the SFS data (Fig. 5c, 5d and 5e). Previous reports suggest that the fluorescence peaks centered in the ranges of 265 295, 295-360, 360-420, 420-460, and 460-520 $\mathrm{nm}$ are assigned to TYL, TPL, MBL, FL, and HL matter, respectively (Pan et al 2017; Su et al., 2016). Area integration of the raw water sample revealed the TPL component contributed $51.75 \%$ abundance followed by MBL (27.24\%), TYL (9.74\%), FL (7.22\%), then HL (4.06\%). There was a significant change in the relative component abundance exhibited by the HL and TPL from raw to disinfection, which was a 16 and 14 times reduction, respectively, whereas there was a 3-, 2- and 3-fold change in TPL, MBL, and FL, respectively $(p>0.05)$. The total removal efficiency of the HL component (93.68\%) was the highest, followed by TYL (92.83\%), FL (71.23\%), TPL (60.58\%), then MBL (58.52\%) (Fig. 5b). Coagulation removed $88.87 \%$ TYL, followed by HL (54.44\%), FL (36.55\%), TPL (30.0.7\%) then MBL (26.22\%), whereas disinfection removed $67.38 \% \mathrm{HL}$, followed by FL (44.92\%), TPL (41.40\%), MBL (40.15\%), then TYL (29.53\%). Thus the main component removal stages were coagulation and disinfection.

Depending on the nature of NOM, the removal efficiencies at the coagulation stage are influenced by the NOM-coagulant properties such as the electrostatic charge interaction, chemical species, and structures, molecular weight distribution, polarity and hydrophobicity (Jarvis, 2004; Su et al., 2017). These results suggest that the TYL component was more amenable to coagulation than the HL component because it has more charged moieties than the HL component. On the other hand, chlorination results in chemical modifications of NOM fractions by selectively targeting double bonds and conjugated functional groups abundant in the HL fraction compared to the TYL fraction (Golea et al., 2017). Depending on the number and distribution of these moieties, there are differential removal rates with the HL fraction compared to TYL component.

\section{Characterising NOM dynamics using 2D-SFS correlation analysis}

Two-dimensional correlation analysis was conducted on the SFS dataset to determine any compositional changes of the fluorescent components due to the treatment processes. Positive auto peaks were observed at the wavelength pairs of 279/279 nm and $320 / 320 \mathrm{~nm}$ on the synchronous map (Fig. 6a). According to Noda's rule, for a wavelength pair $\lambda 1 / \lambda 2$ on the synchronous map, an auto-peak means the transformations at the wavelengths $\lambda 1$ and $\lambda 2$ occur concurrently (Noda and Owasaki, 2004), thus corroborating SFS data which showed a progressive decline in the NOM fractions down the treatment train. The peaks at the excitation wavelengths of 279 and $320 \mathrm{~nm}$ were ascribed to TYL and TPL, respectively (Pan et al., 2017). Asynchronous maps indicate only cross peaks (Fig. 6b). For a wavelength pair $\lambda_{1} / \lambda_{2}$ in the asynchronous map, a positive cross peak indicates that the rate of change happening at the wavelength $\lambda_{1}$ is fast paced compared to that taking place at the wavelength $\lambda_{2}$, while a negative cross-peak indicates the inverse, i.e., the rate of transformation happening at the wavelength $\lambda_{1}$ is retarded when compared to that taking place at the wavelength $\lambda_{2}$ (Hur et

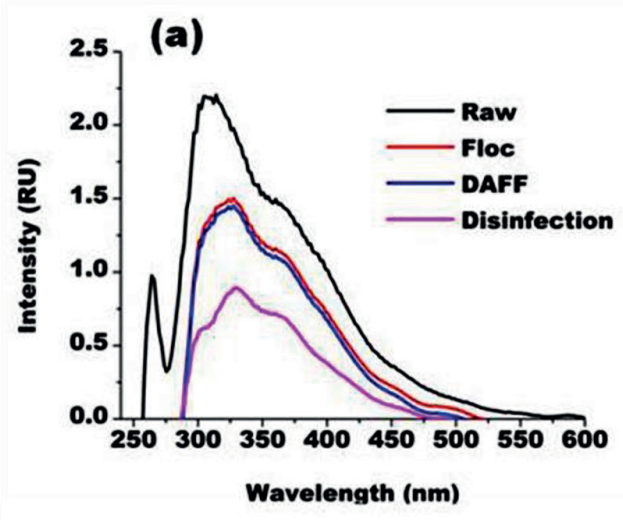

(c)

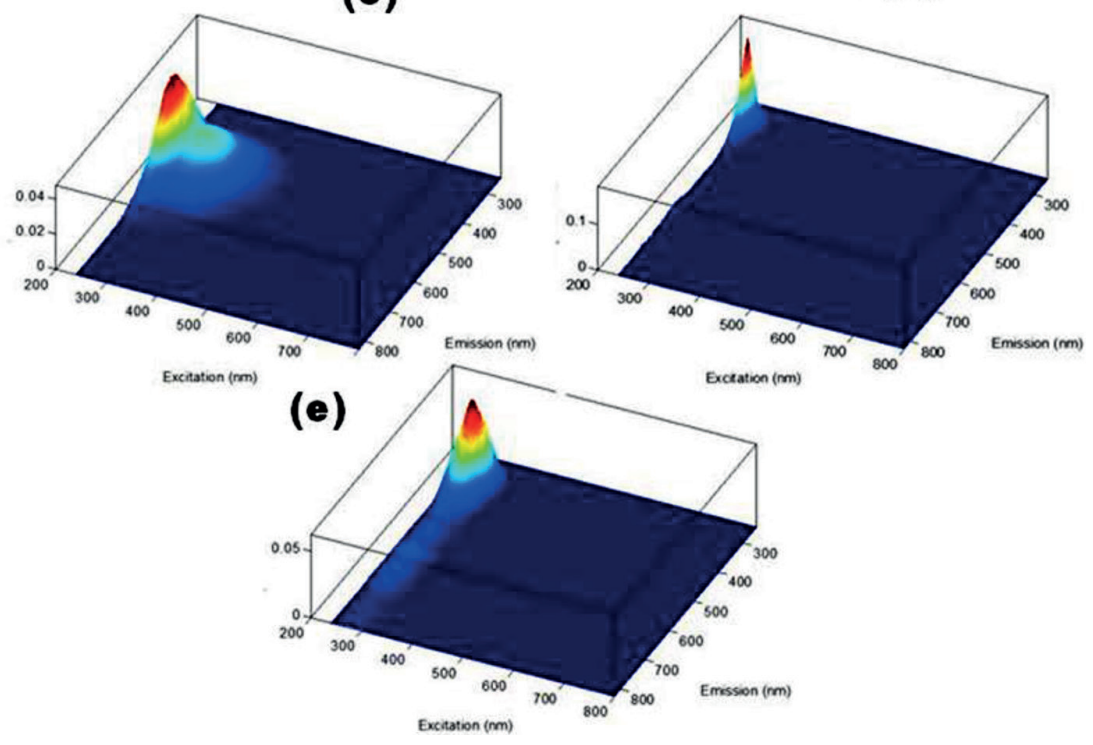

(b)

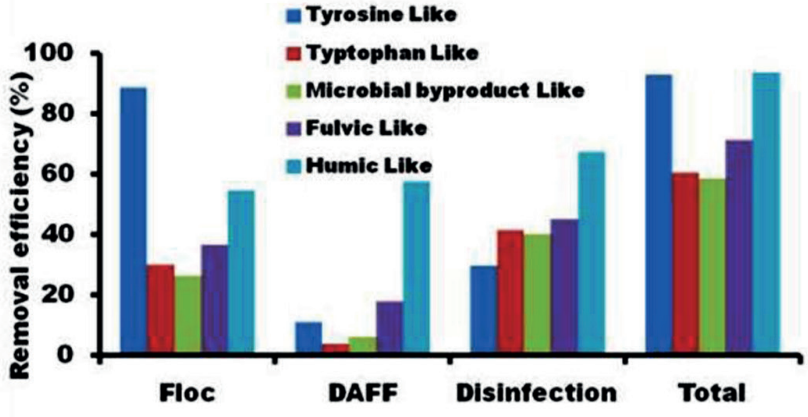

(d) 
al., 2011). Therefore, these results indicate that changes in TYL, TPL, and MBL varied concurrently as water passed through the different treatment stages.

In the asynchronous map (Fig. 6b), two negative cross peaks occurred at 330/279 and 365/279 $\mathrm{nm}$, while weakly positive cross peaks were observed at $410 / 330$ and $480 / 330 \mathrm{~nm}$. Spectral changes at the excitation wavelength of $279 \mathrm{~nm}$ are faster than at the excitation wavelength of 330 and $365 \mathrm{~nm}$, and spectral changes observed at excitation wavelength $330 \mathrm{~nm}$ are faster than at excitation wavelengths of 410 and $480 \mathrm{~nm}$ (Noda and Ozaki., 2004). The peak at $279 \mathrm{~nm}$ was ascribed to TYL matter, while those at 330, 365, 410 and $480 \mathrm{~nm}$ are related to TPL, MBL, FL, and HL matter, respectively. Therefore, based on Noda's rule, the sequence of changing band order was $279 \rightarrow 480 \rightarrow 410$ $\rightarrow 330 \rightarrow 360 \mathrm{~nm}$. This implies the TYL component was more susceptible to treatment, followed by HL, FL, TPL, and MBL, and is consistent with data on the removal efficiency of each component at this WTP.

\section{CONCLUSION}

The assessment of the transformation of NOM due to treatment processes in a WTP was followed using BDOC and polarity fraction dynamics with insights from UV-Vis absorbance with Gaussian fitting, FEEM and SFS spectroscopy combined with two-dimensional correlations. The main findings were: (i) there was a reduction in the intensity and number of Gaussian bands down the treatment train implying the treatment plant was efficient in removing chromophoric moieties; (ii) the HPI fraction was recalcitrant to treatment, and the tyrosine-like component of the HPI fraction was the DBP-limiting reagent; (iii) the $\mathrm{HL}$ and FL of the BDOC were the major substrates for bacterial assimilation; and (iv) TYL, TPL and MBL varied concurrently as water passed through the different treatment stages. This study has revealed the robustness of a multi-dimensional approach of optical methods coupled with chemometric tools, applied for the first time in South Africa, for the assessment of the fate of NOM throughout the treatment processes.

\section{ACKNOWLEDGEMENTS}

The authors are grateful for funding received from the National Research Foundation (NRF) of South Africa, the Water Research
Commission (WRC) of South Africa, and the University of South Africa.

\section{REFERENCES}

BAGHOTH SA (2012) Characterizing natural organic matter in drinking water treatment processes and trains. PhD thesis, Delft University of Technology.

BAGHOTH SA, SHARMA SK and AMY GL (2010) Tracking natural organic matter (NOM) in a drinking water treatment plant using fluorescence excitation-emission matrices and PARAFAC. Water Res. 45 (2) 797-809. https://doi.org/10.1016/j.watres.2010.09.005

BIEROZA M, BAKER A and BRIDGEMAN J (2011) Exploratory analysis of excitation-emission matrix fluorescence spectra with self-organizing maps - A tutorial. Inst. Chem. Eng. 7 (1) 22-31. https://doi.org/10.1016/j.ece.2011.10.002

CHAUKURA N, MOYO W, MAMBA BB and NKAMBULE TI (2018) Abatement of humic acid from aqueous solution using a carbonaceous conjugated microporous polymer derived from waste polystyrene. Environ. Sci. Pollut. Res. 25 (4) 3291-3300. https://doi. org/10.1007/s11356-017-0691-X

CHEN C, LEAVY S, KRASNER SW and SUFFET IH (2014) Applying polarity rapid assessment method and ultrafiltration to characterize NDMA precursors in wastewater effluents. Water Res. 57 115-126. https://doi.org/10.1016/j.watres.2014.02.052

CHEN Z, LI M, WEN Q and REN N (2017) Evolution of molecular weight and fluorescence of ef fl uent organic matter ( EfOM ) during oxidation processes revealed by advanced spectrographic and chromatographic tools. Water Res. 124 566-575. https://doi. org/10.1016/j.watres.2017.08.006

COSTA J, AZZEVEDO JCR, KNAPIK HG and BURROWS HD (2016) Molecular and biomolecular spectroscopy unsupervised component analysis: PCA, POA and ICA data exploring - connecting the dots. Spectrochim. Acta A Molec. Biomolec. Spectroscopy 165 69-84. https://doi.org/10.1016/j.saa.2016.03.048

DONG Q, LI P, HUANG Q, ABDEIHAFEZ AA and CHEN L (2014) Occurrence, polarity and bioavailability of dissolved organic matter in the Huangpu River, China. J. Environ. Sci. (China) 26 (9) 18431850. https://doi.org/10.1016/j.jes.2014.06.020

DRYERDJ, KORSHIN GV, HEITZA and JOLLC (2008) Characterization of proton and copper binding properties of natural organic matter from an Australian drinking water source by differential absorbance spectroscopy. Water Sci. Technol. Water Suppl. 8 (6) 611-614. https:// doi.org/10.2166/ws.2008.140

DRYER D J, KORSHIN, GV and FABBRICINO M (2008) In situ examination of the protonation behavior of fulvic acids using differential absorbance spectroscopy. Environ. Sci. Technol. 42 (17) 6644-6649. https://doi.org/10.1021/es800741u
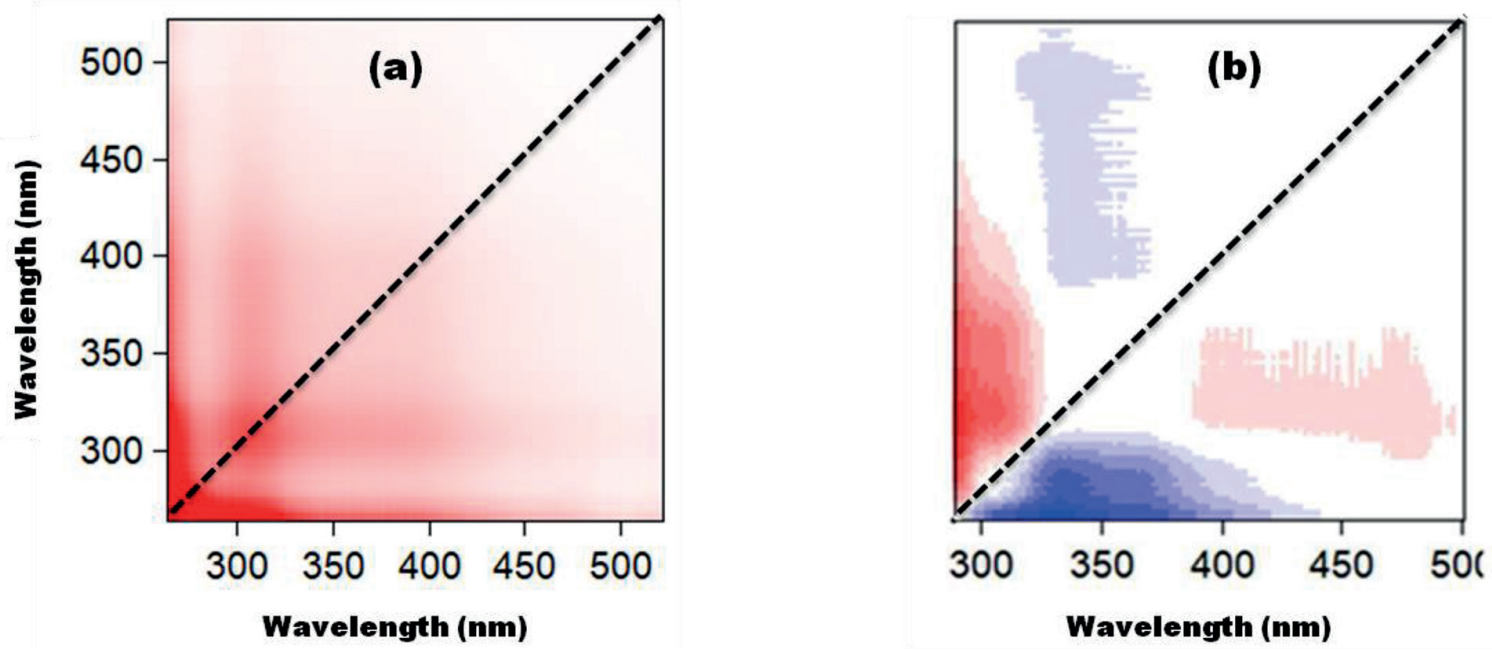

Figure 6. (a) Synchronous 2D correlation map; (b) asynchronous 2D correlation map originating from 260 to $550 \mathrm{~nm}$ region of SFS of NOM in the DWTP. Red indicates a positive correlation, and blue indicates negative correlation; a darker shade indicates a stronger positive or negative correlation. 
EJARQUE E, ELISABET EJARQUE, FREIXA A, VAZQUEZ E, GUARCH A, AMALFITANO S, FAZI S, ROMANÍ AM and BUTTURINI A (2017) Quality and reactivity of dissolved organic matter in a Mediterranean river across hydrological and spatial gradients. Sci. Total Environ. 599-600 (2017) 1802-1812. https://doi. org/10.1016/j.scitotenv.2017.05.113

FILIP Z, PECHER W and BERTHELIN J (2000) Microbial utilization and transformation of humic acid-like substances extracted from a mixture of municipal refuse and sewage sludge disposed of in a landfill. Environ. Pollut. 109 (1) 83-89. https://doi.org/10.1016/ S0269-7491(99)00229-8

GOLEA DM, UPTON A, JARVIS P, MOORE G, SUTHERLAND S, PARSONS SA and JUDD SJ (2017) THM and HAA formation from NOM in raw and treated surface waters. Water Res. 112 226-235. https://doi.org/10.1016/j.watres.2017.01.051

GUO X, YUAN D, JIANG J, ZHANG H and YU DENG (2013) Detection of dissolved organic matter in saline - alkali soils using synchronous fluorescence spectroscopy and principal component analysis Spectrochim. Acta A Molec. Biomolec. Spectroscopy 104 280-286. https://doi.org/10.1016/j.saa.2012.11.081

HE S, YAN M and KORSHIN GV(2015) Spectroscopic examination of effects of iodide on the chloramination of natural organic matter. Water Res. 70 449-457. https://doi.org/10.1016/j.watres.2014.12.024

HE XS, XI BD, LI X, PAN HW, AN D, BAI SG, LI D and CUI DY (2013) Fluorescence excitation-emission matrix spectra coupled with parallel factor and regional integration analysis to characterize organic matter humification. Chemosphere 93 (9) 2208-2215. https://doi.org/10.1016/j.chemosphere.2013.04.039

HENDERSONA RK, BAKERA A, MURPHYA KR, HAMBLYA A, STUETZA RM and KHAN SJ (2009) Fluorescence as a potential monitoring tool for recycled water systems: A review. Water Res. 43 (4) 863-881. https://doi.org/10.1016/j.watres.2008.11.027

HESHAM N (2013) Fate of natural organic matter and formation of disinfection by-products in a conventional water treatment plant. MSc thesis, The American University in Cairo

HUAG,RECKHOWDAandABUSALLOUTI(2015)Correlationbetween SUVA and DBP formation during chlorination and chloramination of NOM fractions from different sources. Chemosphere 130 82-89. https://doi.org/10.1016/j.chemosphere.2015.03.039

HUR J, LEE BM, LEE S and SHIN JK (2014) Characterization of chromophoric dissolved organic matter and trihalomethane formation potential in a recently constructed reservoir and the surrounding areas - Impoundment effects. J. Hydrol. 515 71-80. https://doi.org/10.1016/j.jhydrol.2014.04.035

HUR J, JUNG K and MEE Y (2011) Characterization of spectral responses of humic substances upon UV irradiation using twodimensional correlation spectroscopy. Water Res. 45 (9) 2965-2974 https://doi.org/10.1016/j.watres.2011.03.013

JARVIS P (2004) The impact of natural organic matter on floc structure. $\mathrm{PhD}$ thesis, Cranfield University.

KARAPINAR N, UYAK V, SOYLU S and TOPAL T (2014) Seasonal variations of NOM composition and their reactivity in a low humic water Environ. Progress Sustainable Energ. 33 (3). https://doi.org/10.1002/ep.11878

KASTL G, SATHASIVAN A AND FISHER I (2016) A selection framework for NOM removal process for drinking water treatment. Desalin. Water Treat. 57 (17) 7679-7689. https://doi.org/10.1080/194 43994.2015.1044476

KIM H and YU M (2005) Characterization of natural organic matter in conventional water treatment processes for selection of treatment processes focused on DBPs control. Water Res. 39 4779-4789. https://doi.org/10.1016/j.watres.2005.09.021

KNOWLES AD (2011) Optimizing the removal of natural organic matter in drinking water while avoiding unintended consequences following coagulation. $\mathrm{PhD}$ thesis, Dalhousie University.

KORAK JA, DOTSON AD, SUMMERS RS and ROSARIO-ORTIZ FL (2013) Critical analysis of commonly used fluorescence metrics to characterize dissolved organic matter. Water Res. 49 327-338. https://doi.org/10.1016/j.watres.2013.11.025

KORSHIN GV, SGROI M and RATNAWEERA H (2017) Spectroscopic surrogates for real time monitoring of water quality in wastewater treatment and water reuse. Curr. Opin. Environ. Sci. Health 2 12-19. https://doi.org/10.1016/j.coesh.2017.11.003

LAVONEN E (2015) Tracking changes in dissolved natural organic matter composition. PhD thesis, Swedish University of Agricultural Sciences.
LI P and HUR J (2017) Utilization of UV-Vis spectroscopy and related data analyses for dissolved organic matter (DOM) studies: A review. Crit. Rev. Environ. Sci. Technol. 47 (3) 131-154. https://doi.org/10.10 80/10643389.2017.1309186

LI WT, CAO MJ, YOUNG T, RUF B, MICHAEL DODD M, LI AM and KORSHIN G (2017a) Application of UV absorbance and fluorescence indicators to assess the formation of biodegradable dissolved organic carbon and bromate during ozonation. Water Res. 111 154-162. https://doi.org/10.1016/j.watres.2017.01.009

LI WT, CAO MJ, YOUNG T, RUF B, MICHAEL DODD M, LI AM and KORSHIN G (2017b) Application of UV absorbance and fluorescence indicators to assess the formation of biodegradable dissolved organic carbon and bromate during ozonation. Water Res. 111 154-162 . https://doi.org/10.1016/j.watres.2017.01.009

LIAO X, BEI E, LI S, OUYANG Y, WANG J, CHEN C, ZHANG X, KRASNER SW and SUFFET IH (2015a) Applying the polarity rapid assessment method to characterize nitrosamine precursors and to understand their removal by drinking water treatment processes. Water Res. 87 292-298. https://doi.org/10.1016/j.watres.2015.09.040

LIAO X, BEI E, LI S, OUYANG Y, WANG J, CHEN C, ZHANG X, KRASNER SW and SUFFET IH (2015b) Applying the polarity rapid assessment method to characterize nitrosamine precursors and to understand their removal by drinking water treatment processes', Water Res. 87 292-298. https://doi.org/10.1016/j.watres.2015.09.040

LOBANGA KP, HAARHOFF J and VAN STADEN SJ (2013) Treatability of South African surface waters by enhanced coagulation. Water $S A$ 39 (3) 379-384. https://doi.org/10.4314/wsa.v39i3.6

LOHWACHARIN J, YANG Y, WATANABE N, PHETRAK A and TAKIZAWA S (2014) Removal of DOM and AOC in a full-scale advanced water treatment plant: effects of operational periods of BAC filters. Water Sci. Technol. Water Suppl. 14 (1) 165-172. https:// doi.org/10.2166/ws.2013.185

LYON BA, CORY RM and WEINBERG HS (2014) Changes in dissolved organic matter fluorescence and disinfection byproduct formation from UV and subsequent chlorination/chloramination. J. Hazardous Mater. 264 411-419. https://doi.org/10.1016/j.jhazmat.2013.10.065

MARAIS SS, NDLANGAMANDLA NG, BOPAPE DA, STRYDOMWF, DLAMINI DS, KUVAREGA AT, MAMBA BB and NKAMBULE TI (2016) Natural organic matter (NOM) in South African Waters: Treatability, removal and development of techniques for removal of disinfection by-products in water. WRC Report No. K5/2468/3. Water Research Commission, Pretoria.

MARAIS SS, NCUBE EJ, MSAGATI TAM, HAARHOFF J, NKAMBULE TI and MAMBA BB (2017) Investigation of natural organic matter (NOM) character and its removal in a chlorinated system at Rand Water, South Africa. Water Sci. Technol. Water Suppl. 17 (5) $1287-$ 1297. https://doi.org/10.2166/ws.2017.028

MCDOWELLA WH, ZSOLNAY A, AITKENHEAD-PETERSON JA, GREGORICH EG, JONES DL, JO“DEMANN D, KALBITZ K, MARSCHNER B and SCHWESIG D (2006) A comparison of methods to determine the biodegradable dissolved organic carbon from different terrestrial sources. Soil Biol. Biochem. 38 1933-1942. https://doi.org/10.1016/j.soilbio.2005.12.018

MURPHY KR, STEDMON CA, GRAEBERC D and BRO R (2013) Fluorescence spectroscopy and multi-way techniques. PARAFAC. Anal. Meth. 5 (23) 6557-6566. https://doi.org/10.1039/c3ay41160e

NKAMBULE TI, KRAUSE RWM, HAARHOFF J and MAMBA BB (2012) A three-step approach for removing organic matter from South African water sources and treatment plants. Phys. Chem. Earth 50-52 132-139. https://doi.org/10.1016/j.pce.2012.08.009

NKAMBULE TI (2012a) Natural organic matter (NOM) in South African waters: characterization of NOM, treatability, and method development for effective NOM removal from water. $\mathrm{PhD}$ thesis, University of Johannesburg.

NODA I and OZAKI Y (2005) Two-dimensional correlation spectroscopy: applications in vibrational and optical spectroscopy. Appl. Spectroscopy $\mathbf{5 4}$ 143-165. https://doi.org/10.1016/j. vibspec.2003.12.016

PARK JW, KIM HC, MEYER AS, KIM S and MAENG SK (2016) Influences of NOM composition and bacteriological characteristics on biological stability in a full-scale drinking water treatment plant. Chemosphere 160 189-198. https://doi.org/10.1016/j. chemosphere.2016.06.079

PREST EI, HAMMES F, LOOSDRECHT MCM and VROUWENVELDE 
RJS (2016) Biological stability of drinking water : controlling factors, methods, and challenges. Front. Microbiol. 7 (45) 1-24. https://doi. org/10.3389/fmicb.2016.00045

ROCCARO P, YAN M and KORSHIN GV (2015) Use of log-transformed absorbance spectra for online monitoring of the reactivity of natural organic matter. Water Res. 84 136-143. https://doi.org/10.1016/j. watres.2015.07.029

ROSARIO-ORTIZFL, KOZAWA K, AL-SAMARRAIHN, GERRINGER FW, GABELICH CJ and SUFFET IH (2004) Characterization of the changes in polarity of natural organic matter using solid-phase extraction: Introducing the NOM polarity rapid assessment method (NOM-PRAM). Water Sci. Technol. Water Suppl. 4 (4) 11-18. https:// doi.org/10.2166/ws.2004.0055

ROSARIO-ORTIZ FL, SNYDER S and SUFFET IH (2007) Characterization of the polarity of natural organic matter under ambient conditions by the Polarity Rapid Assessment Method (PRAM). Environ. Sci. Technol. 41 (14) 4895-4900. https://doi org/10.1021/es062151t

SANCHEZ NP, SKERIOTIS AT and MILLER CM (2013) Assessment of dissolved organic matter fluorescence PARAFAC components before and after coagulation e filtration in a full-scale water treatment plant. Water Res. 47 (4) 1679-1690. https://doi.org/10.1016/j.watres.2012.12.032

SHARPLESS CM and BLOUGH NV (2014) The importance of chargetransfer interactions in determining chromophoric dissolved organic matter (CDOM) optical and photochemical properties. Environmental Science: Process. Impacts 16 (4) 654-671. https://doi. org/10.1039/C3EM00573A

SU B, QU Z, HE XS, SONG YH and JIA LM (2016) Characterizing the compositional variation of dissolved organic matter over hydrophobicity and polarity using fluorescence spectra combined with principal component analysis and two-dimensional correlation technique. Environ. Sci. Pollut. Res. 23 9237-9244. https://doi. org/10.1007/s11356-016-6173-8

SU Z, LIU T, YU W, LI X and GRAHAM NJD (2017) Coagulation of surface water: Observations on the significance of biopolymers.
Water Res. 126 144-152. https://doi.org/10.1016/j.watres.2017.09.022 TERRY LG and SUMMERS RS (2018) Biodegradable organic matter and rapid-rate biofilter performance . A review. Water Res. 128234 245. https://doi.org/10.1016/j.watres.2017.09.048

TIJANI JO, FATOBA OO, MADZIVIRE G and PETRIK LF (2014) A review of combined advanced oxidation technologies for the removal of organic pollutants from water. Water Air Soil Pollut. 225 (9) 2102. https://doi.org/10.1007/s11270-014-2102-y

UNIVERSITII, ABDUL H and UNIVERSITI A (2016) Trends on natura organic matter in drinking water sources and its treatment. Int. J. Sci. Res. Environ. Sci. 2 (3) 94-106, 2014. https://doi.org/10.12983/ ijsres-2014-p0094-0106

VITAL M, STUCKI D, EGLI T and HAMMES F (2010) Evaluating the growth potential of pathogenic bacteria in the water. Appl. Environ. Microbiol. 76 (19) 6477-6484. https://doi.org/10.1128/ AEM.00794-10

WANG L and BENJAMIN MM (2016) A multi-spectral approach to differentiate the effects of adsorbent pretreatments on the characteristics of NOM and membrane fouling. Water Res. 98 56-63. https://doi.org/10.1016/j.watres.2016.03.066

WU UJ, MURPHY KR and STEDMON CA (2017) The one-sample PARAFAC approach reveals molecular size distributions of fluorescent components in dissolved organic matter. Environ. Sci. Technol. 51 (20) 11900-11908. https://doi.org/10.1021/acs est.7b03260

YANG X, ZHOU Z, RAJU MN, CAI X and MENG F (2017) Selective elimination of chromophoric and fluorescent dissolved organic matter in a full-scale municipal wastewater treatment plant. J. Environ. Sci. (China) 57 150-161. https://doi.org/10.1016/j. jes.2016.11.003

ZHANG Y, ZHAO X, ZHANG X and PENG S (2015) A review of different drinking water treatments for natural organic matter removal. Water Sci. Technol. Water Suppl. 15 (3) 442-455. https:// doi.org/10.2166/ws.2015.011 